\title{
Short communication: Lymphoproliferative response to lipopolysaccharide and incidence of infections in periparturient dairy cows
}

\author{
Elisabetta Catalani, ${ }^{*}$ Massimo Amadori, $†$ Andrea Vitali, ${ }^{*}$ and Nicola Lacetera*1 \\ *Dipartimento di Scienze e Tecnologie per l'Agricoltura, le Foreste, la Natura e l'Energia, Università degli Studi della Tuscia, Viterbo, 01100, Italy \\ †Laboratorio di Immunologia Cellulare, Istituto Zooprofilattico Sperimentale Lombardia-Emilia Romagna, Brescia, 25124, Italy
}

\begin{abstract}
This preliminary study aimed at assessing whether the in vitro proliferation of peripheral blood mononuclear cells in response to lipopolysaccharide permits individual characterization of periparturient dairy cows, and whether this parameter may be associated with incidence of infections and with some of the single nucleotide polymorphisms located on the toll-like receptor 4 (TLR4) gene. Based on the average response of peripheral blood mononuclear cells to lipopolysaccharide over 7 time points during the transition period, 31 cows were categorized as low (LO), medium (MED), and high (HI) responders. This categorization identified $7 \mathrm{HI}, 19 \mathrm{MED}$, and $5 \mathrm{LO}$ cows, respectively. Genomic DNA was genotyped for P-226 C>G and E3+2021 C $>$ T TLR4 single nucleotide polymorphisms. Monitoring of the health status revealed that 8 of the 31 cows suffered from clinical mastitis, metritis, or interdigital dermatitis during the first $60 \mathrm{~d}$ in milk. The association study pointed out that none of the HI cows and all of the LO cows developed an infection; cows with the CCGT haplotype remained healthy and none of them belonged to the LO responder category.
\end{abstract}

Key words: lipopolysaccharide, infection, toll-like receptor 4

\section{Short Communication}

Bacteria are the primary cause of the most frequent and costly infections in dairy cows: mastitis, metritis, and claw disorders (Seegers et al., 2003; Koenig et al., 2005; Sheldon et al., 2009). The incidence of these infections is particularly high in early lactation, and due to their economic implications, several studies have focused on strategies to better understand and prevent disease occurrence. Lipopolysaccharide is the major component of the outer wall of gram-negative bacteria and several findings testify that the ability

Received March 26, 2013.

Accepted July 19, 2013.

${ }^{1}$ Corresponding author: nicgio@unitus.it to respond to LPS is highly variable in human beings (Kline et al., 1999; Arbour et al., 2000; Stephens et al., 2005). Several cattle studies have also reported large interindividual variability in responses to intravenous injection of LPS (Aiumlamai and Kindahl, 1990; Giri et al., 1990; Semrad and Dubielzig, 1993; Elsasser et al., 2005; Jacobsen et al., 2005).

Recent studies have demonstrated that indicator traits of adaptive immunity may help to identify cows with high or low ability to mount an immune response and also that such ability is associated to some extent with susceptibility to infections (Thompson-Crispi and Mallard, 2012; Thompson-Crispi et al., 2012). Great interest is also being given to genetic factors involved in the interindividual variability to develop an immune response. The toll-like receptors (TLR) play a central role in the immune response to microbial pathogens (Sabroe et al., 2003; Takeda et al., 2003). In particular, TLR4 is the key component of the receptor complex for LPS (Yamamoto and Akira, 2009). The TLR4 gene is highly polymorphic, even in the bovine species (White et al., 2003) and several SNP are under study for a possible implication in infectious diseases (Malley et al., 2003; Schröder and Schumann, 2005; Fukusaki et al., 2007; Hong et al., 2007; Najmi et al., 2010). In cattle, genetic variations in the TLR4 gene were associated with paratuberculosis infection (Mucha et al., 2009; Pinedo et al., 2009) and with other health-related traits in Holstein cows (Sharma et al., 2006, 2008; Wang et al., 2007).

The aim of this preliminary study was to assess whether the in vitro proliferation of peripheral blood mononuclear cells (PBMC) in response to LPS may permit individual characterization of periparturient dairy cows, and whether this feature is associated with some typical infections of early lactation and some of the previously identified SNP located in the TLR4 gene.

The study was carried out on 31 periparturient Holstein cows in a commercial herd with approximately 300 lactating animals. The 31 cows enrolled in the study averaged $2.6 \pm 0.8$ lactations. Cows enrolled in the study were clinically healthy at $21 \mathrm{~d}$ before the expected 
calving. The execution of the study complied with the Italian regulation on animal welfare and protection. Venous blood was collected by jugular venipuncture using sodium heparin $(10 \mathrm{IU} / \mathrm{mL})$ as an anticoagulant, at -21 and $-7 \mathrm{~d}$ from the expected calving and at +7 , $+14,+21,+28$, and $+35 \mathrm{~d}$ after calving. The entire experiment lasted approximately $4 \mathrm{mo}$; the first blood sample was taken on April 7 and the last one was collected on August 9, 2008. Immediately after collection, blood samples were stored in a portable refrigerator and transferred to the laboratory.

The 31 cows under study were carefully monitored for their health status during the last month of pregnancy and the first 60 DIM. Disease cases assessed in the study included clinical mastitis, metritis, and interdigital dermatitis. Disease recording was carried out by a practitioner blinded to the cows' category (see below). Infection was recorded when associated with clinical signs and pharmacological treatments. Due to the low number of cases, the severity of the diseases was not taken into account for the study.

The PBMC were isolated by density gradient centrifugation as described previously (Lacetera et al., 2002). Briefly, blood diluted in PBS (Sigma, St. Louis, MO) was layered over Ficoll-Paque PLUS medium (APB, Milan, Italy) and centrifuged at $600 \times g$ and $18^{\circ} \mathrm{C}$ for $45 \mathrm{~min}$. The mononuclear cell band was recovered and washed twice in PBS. Residual red blood cells were eliminated by hypotonic shock treatment using redistilled water. The PBMC viability was determined by the trypan blue exclusion method (Strober, 2001) and typically exceeded $90 \%$. Peripheral blood mononuclear cells were resuspended at $1 \times 10^{6}$ viable cells $/ \mathrm{mL}$ in RPMI 1640 medium containing $25 \mathrm{~m} M$ HEPES $+10 \%$ heat-inactivated fetal bovine serum, $2 \mathrm{mM}$ L-glutamine, $100 \mathrm{U}$ of penicillin, $100 \mu \mathrm{g}$ of streptomycin, and $0.25 \mu \mathrm{g}$ of amphotericin B $/ \mathrm{mL}$ (Sigma). The proliferative response of PBMC to LPS $(20 \mu \mathrm{g} / \mathrm{mL}$, from Escherichia coli O111:B4; Sigma) was determined by an ELISA kit (GE Healthcare, Chalfont St. Giles, UK) based on the measurements of 5-bromo-2'-deoxyuridine (BrdU) incorporation during DNA synthesis in proliferating cells. The time between blood collection and establishment of cultures was less than $6 \mathrm{~h}$. The BrdU was added to wells after $48 \mathrm{~h}$ of incubation at $39^{\circ} \mathrm{C}$ in an atmosphere of $95 \%$ air and $5 \% \mathrm{CO}_{2}$; cell proliferation was quantified after an incubation for an additional $18 \mathrm{~h}$. Control wells contained the PBMC suspension without LPS or BrdU. Values of PBMC proliferation were expressed as the optical density (OD) for test wells minus the OD for control wells without BrdU.

The average individual responses to LPS in terms of proliferation (7 time points) were used to categorize cows as low (LO), medium (MED), or high (HI) re- sponders. The proportion of $\mathrm{HI}$ and $\mathrm{LO}$ responders was defined as 1 standard deviation above and below the mean, respectively (Begley et al., 2009).

Genomic DNA was isolated from whole blood and genotyped by a private company (KBioscience, Hoddesdon, UK) for $2 \mathrm{SNP}$ in the TLR 4 gene previously described in Holstein cattle (White et al., 2003; Sharma et al., 2006). The first one was the SNP in the $5^{\prime}$ untranslated region (UTR) at the 226-bp position, in the putative promoter region (P-226 $\mathrm{C}>\mathrm{G}$ ); the second was in exon 3 at the 2,021-bp position $(\mathrm{E} 3+2021 \mathrm{C}>\mathrm{T})$. The best haplotype reconstruction was performed by PHASE 2.1 software (Stephens et al., 2004). Briefly, this program implements a Bayesian statistical method for reconstructing haplotypes from population genotype data (in our case, from data relative to 31 cows) and provides a list of haplotypes with a summary of the frequency with which each haplotype occurs in this best reconstruction.

The chi-squared goodness-of-fit test was used to compare the observed number of cows infected within the 3 categories (HI, MED, and LO) with the number of cows expected to be infected under the assumption that infected cows would be randomly distributed throughout HI, MED, and LO categories. If differences calculated by the chi-squared goodness of fit were significant, the categories with the highest and lowest frequencies of cows infected were tested to evaluate differences from the average of all categories combined (Vitali et al., 2009). In practice, the overall mean was set at a relative risk (RR) of 1, and variation in the number of cows infected within categories was expressed as the difference in RR between the categories with the highest and lowest frequency of infected animals. Significance and marginal significance were declared at $P<0.05$ and $P<0.1$, respectively. The associations of haplotypes with incidence of infections and with HI, MED, and LO categories were estimated by the same chi-squared goodness-of-fit analysis.

The kinetics of PBMC proliferation (expressed in OD) in the 3 cow categories was studied by a repeatedmeasures ANOVA. Multiple comparisons were carried out with the Bonferroni post hoc test. Data were reported as least squares means \pm standard error, and significance between time points was declared at $P<$ 0.05 .

The mean values of the proliferative response (OD) of PBMC to LPS in the 3 cow categories during the whole experimental period were $0.53 \pm 0.07$ for $\mathrm{LO}$ cows $(\mathrm{n}=5), 1.43 \pm 0.25$ for MED cows $(\mathrm{n}=19)$, and $2.30 \pm 0.52$ for HI cows $(\mathrm{n}=7)$. The ability of PBMC to proliferate in response to LPS declined progressively in HI and MED cows until d 28 after calving, whereas it did not change in LO cows (Figure 1). 


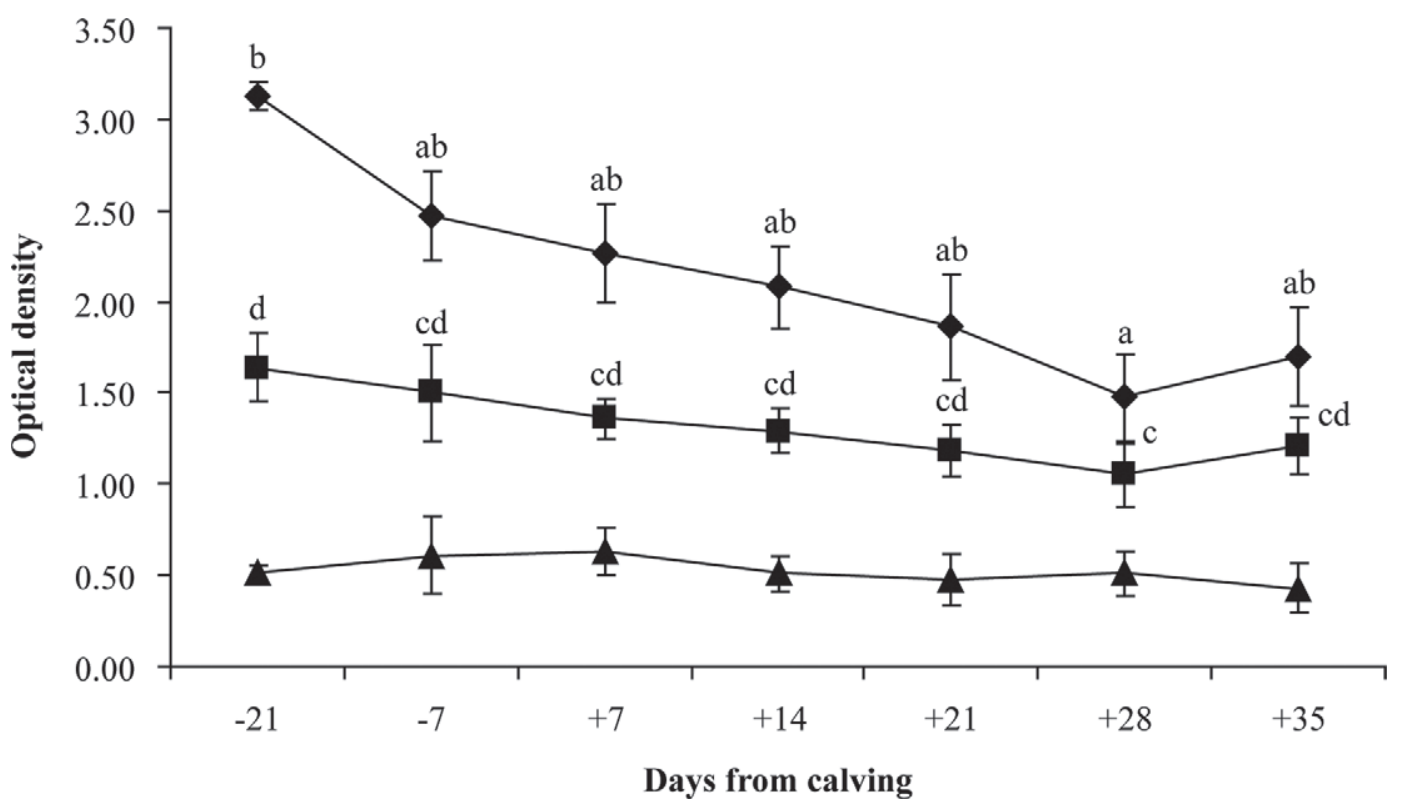

Figure 1. Kinetics of the proliferative responses of peripheral blood mononuclear cells to LPS in high (HI; $\bullet$ ), medium (MED; $\mathbf{\square})$ and low $(\mathrm{LO} ; \boldsymbol{\Lambda})$ responder cows. Values are expressed as mean $\pm \mathrm{SE}$. Different letters $(\mathrm{a}-\mathrm{d})$ indicate significant differences $(P<0.05)$ within the 3 cow categories (HI, MED, and LO).

The 3 groups of cows were homogeneous for parity $(2.7 \pm 0.9,2.4 \pm 1.0$, and $2.6 \pm 1.1$ lactations for $\mathrm{LO}$, MED, and HI cows, respectively) and for actual days before calving at the beginning of this study (19.3 \pm $0.9,20.6 \pm 1.9$, and $19.5 \pm 1.3 \mathrm{~d}$ before calving for LO, MED, and HI cows, respectively). In addition, it should be noted that cows belonging to the 3 categories were uniformly distributed over the entire study period (not shown). Furthermore, in the latter regard, an ANOVA carried out on the same data set for a different purpose pointed out no significant effects of the calving season on PBMC proliferation (Catalani et al., 2010).

Monitoring of the health status revealed that 8 cows developed clinical infections during the first 60 DIM. In particular, infected cows suffered from mastitis $(\mathrm{n}=5)$, metritis $(n=2)$, or interdigital dermatitis $(n=1)$. No clinical signs of diseases were detected before calving.

None of the HI cows suffered from infections, 5 out of 5 LO cows developed infections, and the remaining 3 cows that developed infections belonged to the MED category. A statistically significant association was found between HI, MED, and LO categories and incidence of infection $(P<0.001)$. Results of the RR analysis for the cows' categories with the highest and lowest frequency of infections (LO and HI, respectively), pointed out that the RR of infections for $\mathrm{LO}$ cows was highly significant $(P<0.001)$ and equal to 6.5 , whereas that for $\mathrm{HI}$ was only marginally significant $(P=0.076)$.

The estimated frequencies of all the haplotypes are reported in Table 1. The most frequent haplotype was
CC (haplotype 1), with an estimated frequency of $64 \%$. Two other haplotypes with a moderate frequency were GC (haplotype 2: 22.5\%) and GT (haplotype 3: 12.3\%), whereas the haplotype CT (haplotype 4) was estimated at a very low frequency $(1.3 \%)$.

No significant association was found between haplotypes and either incidence of infection or LPS response categories. However, none of the cows with haplotypes 3 and 4 developed infections, and the risk of getting infected for cows with haplotype 3 was marginally significant $(P=0.08)$ compared with the risk of the cows under study as a whole. Finally, cows with haplotypes 3 and 4 did not include cows belonging to the LO category (Table 2).

The results of this study confirm large interindividual variability in the capacity of PBMC from periparturient dairy cows to respond in vitro to LPS in terms of proliferation. Even if novel, these findings are consistent with those from previous studies showing strong

Table 1. Toll-like receptor 4 haplotype reconstruction and estimated frequencies

\begin{tabular}{lccc}
\hline & \multicolumn{2}{c}{$\mathrm{SNP}$} & \\
\cline { 2 - 3 } Haplotype & $\mathrm{P}-226 \mathrm{C}>\mathrm{G}$ & $\mathrm{E}+2021 \mathrm{C}>\mathrm{T}$ & $\begin{array}{c}\text { Frequency } \\
(\%)\end{array}$ \\
\hline 1 & $\mathrm{C}$ & $\mathrm{C}$ & 64.0 \\
2 & $\mathrm{G}$ & $\mathrm{C}$ & 22.5 \\
3 & $\mathrm{G}$ & $\mathrm{T}$ & 12.3 \\
4 & $\mathrm{C}$ & $\mathrm{T}$ & 1.3 \\
\hline
\end{tabular}


Table 2. Toll-like receptor 4 haplotypes, health status, and categories of response to LPS (HI $=$ high responders; MED = medium responders; $\mathrm{LO}=$ low responders) of cows under study (values are no. in each response category)

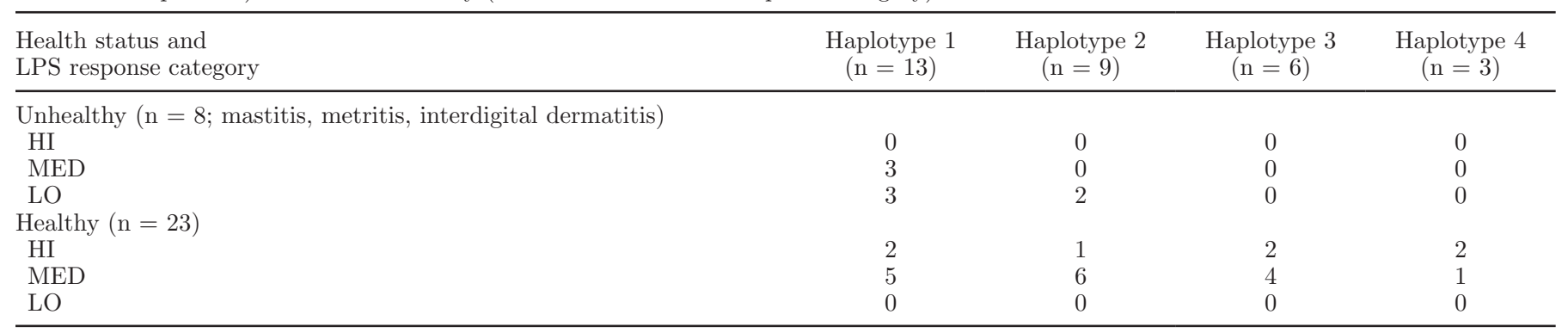

interindividual variability of cattle to respond to intravenous LPS injection (Aiumlamai and Kindahl, 1990; Giri et al., 1990; Semrad and Dubielzig, 1993; Elsasser et al., 2005; Jacobsen et al., 2005).

Second, results reported herein indicate that categorization of periparturient cows on the basis of the ability of PBMC to proliferate following LPS stimulation, which may be considered as a cell-mediated immune response trait (Gershwin et al., 1995), may permit a certain prediction of the risk of cows to develop bacterial infections after calving. In detail, cows characterized by a low response of PBMC to LPS have a risk of developing postcalving bacterial infections 6.5 times higher than cows belonging to the 3 categories considered as a whole. Furthermore, our findings support, to a certain extent, results from recent, larger in vivo studies indicating that cows classified as low, average, and high responders on the basis of a general ability to mount cell-mediated and antibody-mediated immune responses have a different risk of getting diseases after calving (Thompson-Crispi and Mallard, 2012; Thompson-Crispi et al., 2012).

Altogether, results of the SNP analysis suggest that the TLR 4 haplotype may influence immune responsiveness and resistance to infections in transition dairy cows. However, in terms of statistical significance, results of the association studies relative to TLR 4 haplotypes are in line with those reported by Opsal and colleagues (2008) who found no significant association between TLR2 and TLR4 SNP and clinical mastitis in a Norwegian Red cattle population, but contrast with those reported by others (Goldammer et al., 2004; Sharma et al., 2006; Wang et al., 2007), who indicated TLR2 and TLR 4 as possible candidate genes for resistance to mastitis.

Resistance to infections is a complex trait underlying different and highly specific protection strategies, which involve several functions/genes to be investigated. However, even if a limited number of animals were included in this study, the results reported herein support previous findings suggesting that immune re- sponse traits may help predict the risk of infections in dairy cows and also that the TLR 4 gene is likely to be part of the gene set responsible for disease resistance.

\section{ACKNOWLEDGMENTS}

The authors gratefully acknowledge Ministero delle Politiche Agricole, Alimentari e Forestali (MIPAF; Rome, Italy; SELMOL Project) and Società Italiana Veterinaria Agricola Milano (SIVAM S.P.A.; Casalpusterlengo, Italy) for funding and Giorgina Kuzminsky (Dipartimento di scienze e tecnologie per l'Agricoltura, le Foreste, la Natura e l'Energia, Università degli Studi della Tuscia, Viterbo, Italy) for performing the proliferation tests.

\section{REFERENCES}

Aiumlamai, S., and H. Kindahl. 1990. Clinical and blood biochemical changes during induction of endotoxaemia in heifers. Acta Vet. Scand. 31:501-504.

Arbour, N. C., E. Lorenz, B. C. Schutte, J. Zabner, J. N. Kline, M. Jones, K. Frees, J. L. Watt, and D. A. Schwartz. 2000. TLR mutations are associated with endotoxin hyporesponsiveness in humans. Nat. Genet. 25:187-191.

Begley, N., F. Buckley, K. M. Pierce, A. G. Fahey, and B. A. Mallard 2009. Differences in udder health and immune response traits of Holstein-Friesians, Norwegian Reds, and their crosses in second lactation. J. Dairy Sci. 92:749-757.

Catalani, E., M. Amadori, A. Vitali, U. Bernabucci, A. Nardone, and N. Lacetera. 2010. The Hsp72 response in peri-parturient dairy cows: Relationships with metabolic and immunological parameters. Cell Stress Chaperones 15:781-790.

Elsasser, T. H., J. W. Blum, and S. Kahl. 2005. Characterization of calves exhibiting a novel inheritable TNF- $\alpha$ hyperresponsiveness to endotoxin: Associations with increased pathophysiological complications. J. Appl. Physiol. 98:2045-2055.

Fukusaki, T., N. Ohara, Y. Hara, A. Yoshimura, and K. Yoshiura. 2007. Evidence for association between a toll-like receptor 4 gene polymorphism and moderate/severe periodontitis in the Japanese population. J. Periodontal Res. 42:541-545.

Gershwin, L. J., S. Krakowka, and R. G. Olsen. 1995. Assays for T lymphocyte function. Pages 104-106 in Immunology and Immunopathology of Domestic Animals. L. L. Duncan, ed. Mosby Year Book Inc., St. Louis, MO.

Giri, S. N., P. Emau, J. S. Cullor, G. H. Stabenfeldt, M. L. Bruss, R. H. Bondurant, and B. I. Osburn. 1990. Effects of endotoxin infusion on circulating levels of eicosanoids, progesterone, cortisol, glucose and lactic acid, and abortion in pregnant cows. Vet. Microbiol. 21:211-231. 
Goldammer, T., H. Zerbe, A. Molenaar, H. J. Schuberth, R. M. Brunner, S. R. Kata, and H. M. Seyfert. 2004. Mastitis increases mammary mRNA abundance of $\beta$-defensin 5 , toll-like-receptor 2 (TLR2), and TLR 4 but not TLR9 in cattle. Clin. Diagn. Lab. Immunol. 11:174-185.

Hong, J., E. Leung, A. G. Fraser, T. R. Merriman, P. Vishnu, and G. W. Krissansen. 2007. TLR2, TLR 4 and TLR 9 polymorphisms and Crohn's disease in a New Zealand Caucasian cohort. J. Gastroenterol. Hepatol. 22:1760-1766.

Jacobsen, S., T. Toelboell, and P. H. Andersen. 2005. Dose dependency and individual variability in selected clinical, haematological and blood biochemical responses after systemic lipopolysaccharide challenge in cattle. Vet. Res. 36:167-178.

Kline, J. N., J. D. Cowden, G. W. Hunninghake, B. C. Schutte, J. L. Watt, C. L. Wohlford-Lenane, L. S. Powers, M. P. Jones, and D. A. Schwartz. 1999. Variable airway responsiveness to inhaled lipopolysaccharide. Am. J. Respir. Crit. Care Med. 160:297-303.

Koenig, S., A. R. Sharifi, H. Wentrot, D. Landmann, M. Eise, and H. Simianer. 2005. Genetic parameters of claw and foot disorders estimated with logistic models. J. Dairy Sci. 88:3316-3325.

Lacetera, N., U. Bernabucci, B. Ronchi, D. Scalia, and A. Nardone. 2002. Moderate summer heat stress does not modify immunological parameters of Holstein dairy cows. Int. J. Biometeorol. 46:33-37.

Malley, R., P. Henneke, S. C. Morse, M. J. Cieslewicz, M. Lipsitch, C. M. Thompson, E. Kurt-Jones, J. C. Paton, M. R. Wessels, and D. T. Golenbock. 2003. Recognition of pneumolysin by toll-like receptor 4 confers resistance to pneumococcal infection. Proc. Natl. Acad. Sci. USA 100:1966-1971.

Mucha, R., M. R. Bhide, E. B. Chakurkar, M. Novak, and I. Mikula Sr.. 2009. Toll-like receptors TLR1, TLR2 and TLR4 gene mutations and natural resistance to Mycobacterium avium subsp. paratuberculosis infection in cattle. Vet. Immunol. Immunopathol. 128:381-388.

Najmi, N., G. Kaur, S. K. Sharma, and N. K. Mehra. 2010. Human toll-like receptor 4 polymorphisms TLR4 Asp299Gly and Thr399Ile influence susceptibility and severity of pulmonary tuberculosis in the Asian Indian population. Tissue Antigens 76:102-109.

Opsal, M. A., S. Lien, S. Brenna-Hansen, H. G. Olsen, and D. I. Våge. 2008. Association analysis of the constructed linkage maps covering TLR2 and TLR4 with clinical mastitis in Norwegian Red cattle. J. Anim. Breed. Genet. 125:110-118.

Pinedo, P. J., C. D. Buergelt, G. A. Donovan, P. Melendez, L. Morel, R. Wu, T. Y. Langaee, and D. O. Rae. 2009. Candidate gene polymorphisms (BoIFNG, TLR 4, SLC11A1) as risk factors for paratuberculosis infection in cattle. Prev. Vet. Med. 91:189-196.

Sabroe, I., R. C. Read, M. K. Whyte, D. H. Dockrell, S. N. Vogel, and S. K. Dower. 2003. Toll-like receptors in health and disease: Complex questions remain. J. Immunol. 171:1630-1635.

Schröder, N. W. J., and R. R. Schumann. 2005. Single nucleotide polymorphisms of toll-like receptors and susceptibility to infectious disease. Lancet Infect. Dis. 5:156-164.
Seegers, H., C. Fourichon, and F. Beaudeau. 2003. Production effects related to mastitis and mastitis economics in dairy cattle herds. Vet. Res. 34:475-491.

Semrad, S. D., and R. Dubielzig. 1993. Effect of phenylbutazone and repeated endotoxin administration on hemostasis in neonatal calves. Am. J. Vet. Res. 54:1339-1346.

Sharma, B. S., I. Leyva, F. Schenkel, and N. A. Karrow. 2006. Association of toll-like receptor 4 polymorphisms with somatic cell score and lactation persistency in Holstein bulls. J. Dairy Sci. 89:3626-3635.

Sharma, B. S., J. Mount, and N. A. Karrow. 2008. Functional characterization of a single nucleotide polymorphism in the $5^{\prime}$ UTR region of the bovine toll-like receptor 4 gene. Dev. Biol. (Basel) $132: 331-336$

Sheldon, I. M., J. Cronin, L. Goetze, G. Donofrio, and H. J. Schuberth. 2009. Defining postpartum uterine disease and the mechanisms of infection and immunity in the female reproductive tract in cattle. Biol. Reprod. 81:1025-1032.

Stephens, M, N. J. Smith, and P. Donnelly. 2004. Documentation for PHASE, version 2.1. Department of Statistics, University of Washington, Seattle.

Stephens, R. C. M., C. M. N. O'Malley, R. J. Frumento, M. G. Mythen, and E. Bennett-Guerrero. 2005. Low-dose endotoxin elicits variability in the inflammatory response in healthy volunteers. J. Endotoxin Res. 11:207-212.

Strober, W. 2001. Trypan blue exclusion test of cell viability. Current Protoc. Immunol. Appendix 3B. A.3B.1-A.3B.2. 10.1002/0471142735.ima03bs21.

Takeda, K., T. Kaisho, and S. Akira. 2003. Toll-like receptors. Annu. Rev. Immunol. 21:335-376.

Thompson-Crispi, K. A., B. Hine, M. Quinton, F. Miglior, and B. A Mallard. 2012. Short communication: Association of disease incidence and adaptive immune response in Holstein dairy cows. J. Dairy Sci. 95:3888-3893.

Thompson-Crispi, K. A., and B. A. Mallard. 2012. Type 1 and type 2 immune response profiles of commercial dairy cows in four regions of Canada. Can. J. Vet. Res. 76:120-128.

Vitali, A., M. Segnalini, L. Bertocchi, U. Bernabucci, A. Nardone, and N. Lacetera. 2009. Seasonal pattern of mortality and relationships between mortality and temperature humidity index in dairy cows. J. Dairy Sci. 92:3781-3790.

Wang, X., S. Xu, X. Gao, H. Ren, and J. Chen. 2007. Genetic polymorphism of TLR 4 gene and correlation with mastitis in cattle. J. Genet. Genomics 34:406-412.

White, S. N., K. H. Taylor, C. A. Abbey, C. A. Gill, and J. E. Womack. 2003. Haplotype variation in bovine toll-like receptor 4 and computational prediction of a positively selected ligand-binding domain. Proc. Natl. Acad. Sci. USA 100:10364-10369.

Yamamoto, M., and S. Akira. 2009. Lipid A receptor TLR4-mediated signaling pathways. Adv. Exp. Med. Biol. 667:59-68. 